\title{
An intelligent differential protection of power transformer based on artificial neural network
}

\author{
Ali Nathim Hamoodi, Mohammed Ahmed Ibrahim, Bashar Muhammed Salih \\ Department of Power Techniques Engineering, Technical College of Engineering, Northern Technical University, Mosul, Iraq
}

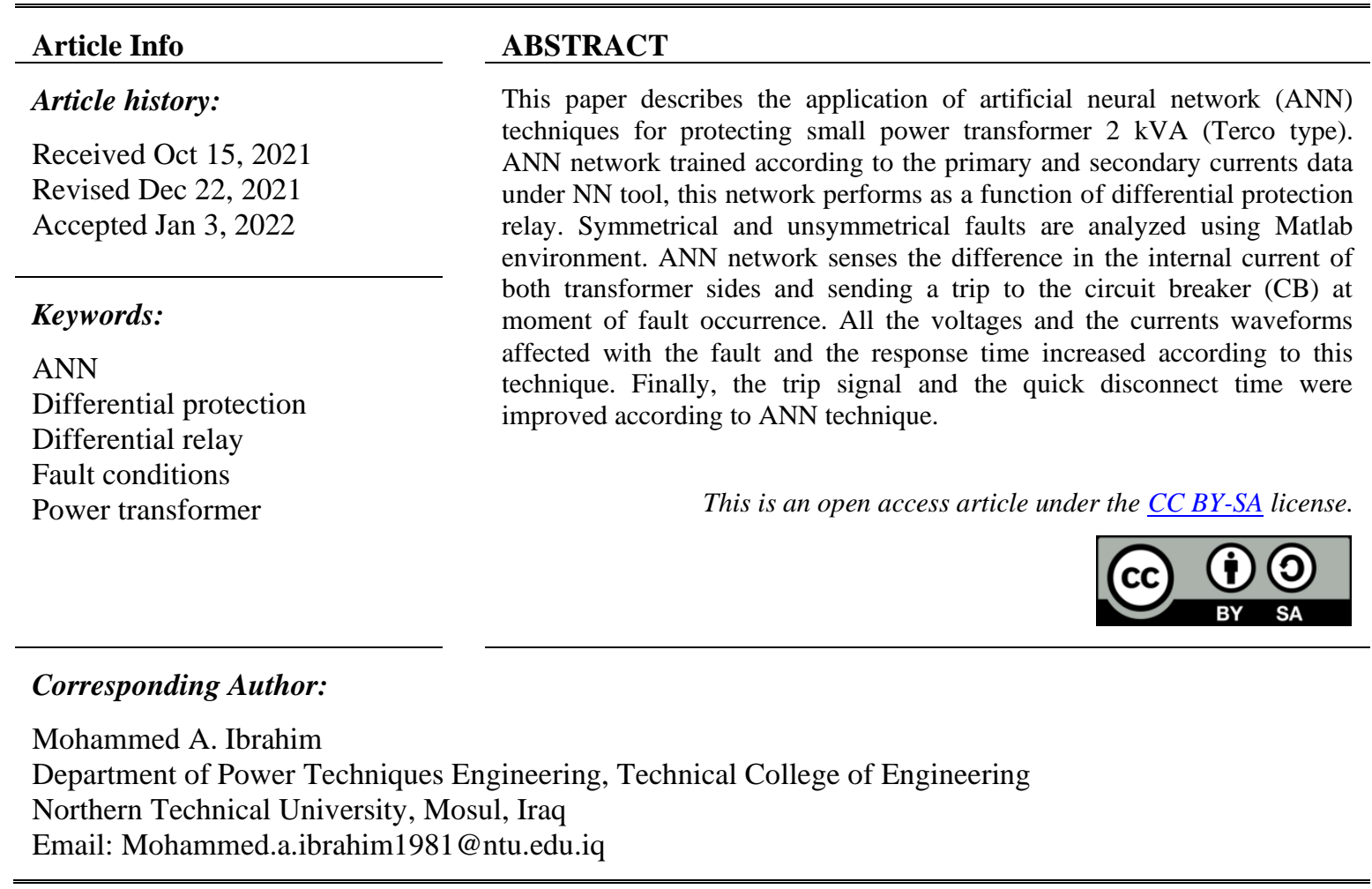

\section{INTRODUCTION}

Transformer protection methods are focusing on differential protection and the attempts to improve the transformer protection, were basing on a comparison between no fault and interior fault [1]. Power transformer protection is critical for the power system operation. Among the many different operations of power transformer, another widely used method is the differential operation [2]. Security, sensitivity, dependability, selectivity, reliability, and speed were the primary requirements for power system protection. The protection system should be capable of detecting flaws in protection zones. A three-phase transformer's primary and secondary windings are protected from faults using the differential protection scheme [3]. This method is based on distinguishing between operation states and faults [4]. In many recognitions or pattern problems, artificial neural network (ANN) algorithms are implemented successfully as investigated by the researchers. ANN techniques are considered a healthy condition for recognition [5]. Fault analysis can assist in choosing and developing the best apparatus for protection. Circuit breaker (CB) and its specifications relies on triple line fault should be introspedted because of the large value of triple line fault current as comparison with another fault currents. The objective of this projeced is to study the balance and unbalance faults. By utilizing MATLAB simulation types [6].

\section{CASE STUDY OBJECTIVE}

The study objective of this work is to detect all fault types with their classifiers and reduce the delay time based on ANN technique and transformer protection only during internal faults according to their zone. The reason for using ANN was to enhance the differential relay reliability without using the fourth harmonic 
method. ANN algorithm type that used in this work was back propagation, also ANN technique made an adabtive process any fault classifier.

\section{LITERATURE REVIEW}

Varghese and George [7], presented in thier paper the improved clasifiction for differential protection in the power transformer. This fault classification was done by using ANN, they used back propagation neural networks but the results for fault classifications were incorrect due to the wrong selection of threshold value. They included that the trip signal must be preprocessed by using ANN before being sent to the $\mathrm{CB}$.

Miriyala et al. [8], used ANN for power transformer protection to detect the internal fault. They conclude that the ANN was successful in assorting the kind of event by given the extract features as an input. They conclude that the fault impedance and other parameters were different from those utilized the learning of ANN, therefore may be need to add a database of learning, record bad fouls ranked and re-train the neural network.

Sahu and Vaidya [9], studied how could be improved the protection algorithm-based ANN. They concluded that the proposed ANN algorithem don't use the harmonic components as the basis of the relay decision and its simplicity, also ANN technicque to discrement between inrush current and internal fault. The ANN technique was able to recognize between current transformer (CT) saturation and other operation terms.

Shah and Parmar [10], applied ANN in the power transformer protection, where its technique was tested by varying learning rate, hidden layer, momentum factor and the number of nodes in the hidden layer. They concluded that the ANN has to surpass the performance of convential ways and gave an indication to apply smant relay for protection the power transformer at very less operation time.

Islam and Kabir [11], worked on power transformer protection, the proposed scheme was feed forward ANN has used as a fault classifier. They concluded that at various operating conditions for internal fault, the output results were near to the target value.

\section{THE PROPOSED METHOD}

The variance between the primary and secondary for CTs must be equal to zero, that means the transformer does not distinguish a fault. No lessees in the perfect power transformer, there for no operating current. ANN technique used to preprocess the trip signal in order to give true signal. Core losses and eddy current showed practically in the transformer [12]-[14].

Figure 1 depicts the first phase of a three-phase differential protection system (DPS). A couple of CTs enclosed the protection equipment. Because of the CTs natural proclivity, differential relay protection will not provide back up protection in relation to the rest of the system equipment; as a result, this type of protection diagram is commonly use as a unit protection schedule. At no fault conditions, the current IP is similar to that get out from the protection equipment at each instant. When the CTs A respected to the aviator wire of CTs A is lambing a current to:

$\mathrm{I}_{\mathrm{AS}}=\alpha_{\mathrm{A}} \mathrm{I}_{\mathrm{p}}-\mathrm{I}_{\mathrm{Ae}}$

Also, for (CT) B, as shown in (2):

$$
\mathrm{I}_{\mathrm{BS}}=\alpha_{\mathrm{B}} \mathrm{I}_{\mathrm{p}}-\mathrm{I}_{\mathrm{Be}}
$$

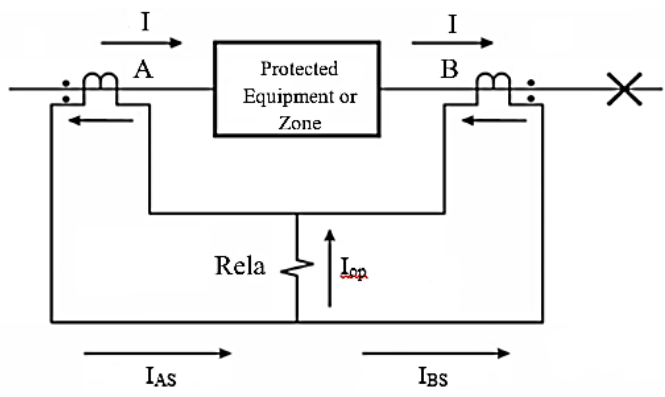

Figure 1. Differentials relay current at the time for out of zone 
Considering equal ratio of $\mathrm{CT} \mathrm{A}$ and $\mathrm{B}, \alpha \mathrm{A}=\alpha \mathrm{B}=\alpha$, the lop is:

$$
\mathrm{I}_{\mathrm{AS}}=\alpha_{\mathrm{A}} \mathrm{I}_{\mathrm{p}}-\mathrm{I}_{\mathrm{Ae}}
$$

The relay operating current is extremely low when the relay is out of zone, but it does not equal zero. When an internal fault (inside zone) occurs, the input current differs from the output current, and the differential relay sends a trip to the CB, as illustrated in Figure 2 [14]-[16].

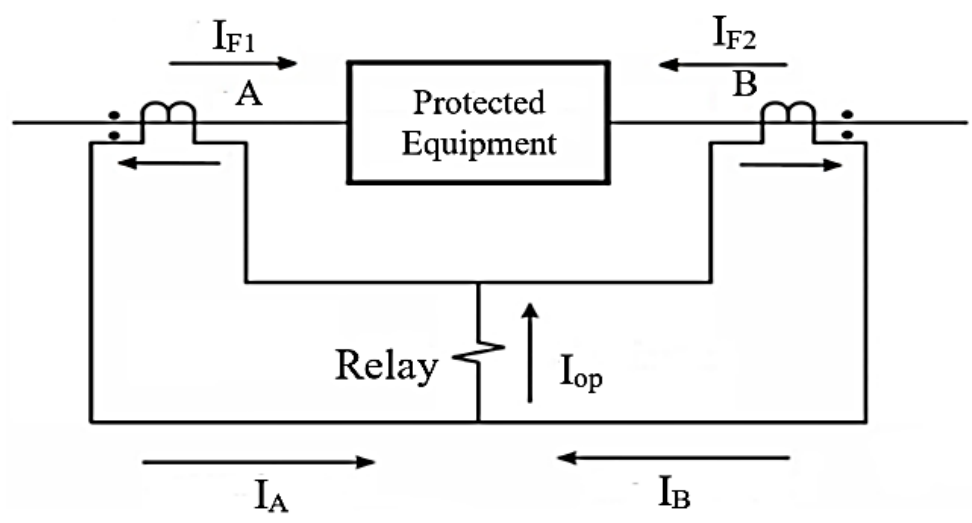

Figure 2. Equivalent circuit of differential relay for single phase

In terms of operating relay characteristics, its bias used for power transformer protection. Figure 3 illustrates relationship between the differential current and the restring current (operation relay characteristics) [17].

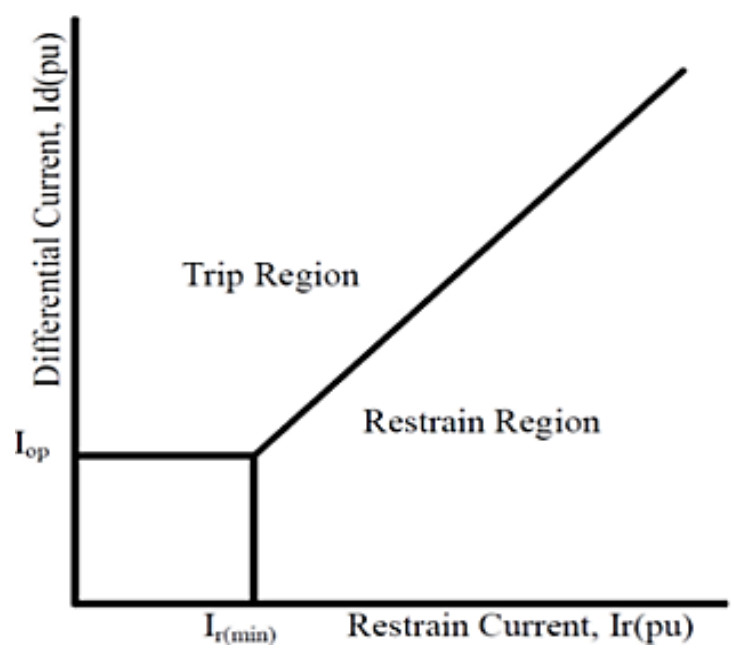

Figure 3. Differential relay characteristics

When the ratio of the pickup is bigger than the bias setting therefor, this ratio value will fall in the tripping region (positive region), otherwise if this ratio is smaller than the bias setting then this ratio value located fall in the blocking region (negative reign) [18], [19]. When faults occur outside of zone, the effect of restraining coils on the operating coils in the types of relays produces conflicting torque, preventing the relay from operating. When fault occurs within the zone (internal fault), the operating torque will become higher than the bias torque, which in turn will operate the relay. The bias torque is adapted by conversion the turns number on the restraining coils [20], [21]. Figure 4 represents the flowchart of differential relay protection for single line power transformer. 


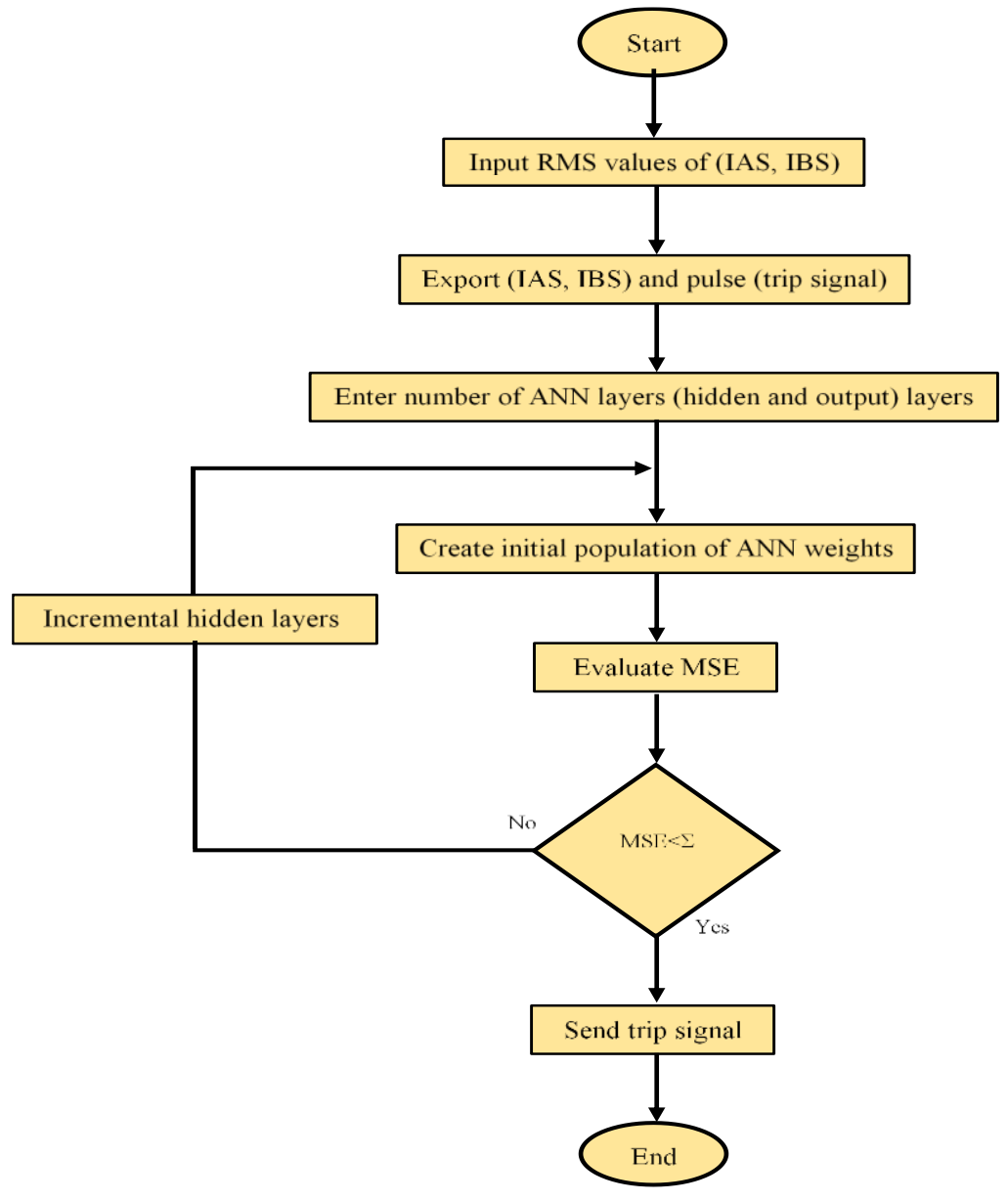

Figure 4. Flowchart of ANN structure for power transformer protection

\section{MATERIALS AND METHOD}

Data for this work was taken from Sweden transformer company (Terco Company). A 2 KVA power transformer as shown in Figure 5 was depended in this work and its data are illustrated in Table 1.

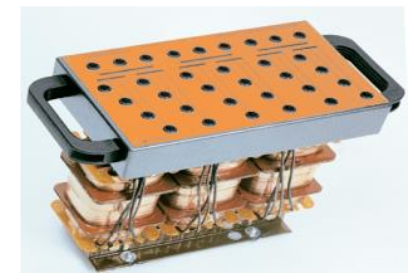

Figure 5. Terco-prototype 2 KVA power transformer

Table 1. Specifications of power transformer Terco type (MV1915)

\begin{tabular}{lc}
\hline \multicolumn{1}{c}{ Parameters } & Terco company \\
\hline Ratings & $(2 \mathrm{kVA}), 50-60 \mathrm{~Hz}, 230 / 2 \times 66.5 \mathrm{~V} / \mathrm{phase}$ \\
Primary voltage of transformer & $0-133-230 \mathrm{~V} \pm 5 \%$ per phase \\
Secondary voltage of transformer & Two $0.0665 \mathrm{kV}$ windings per phase \\
Secondary tapings & $0-38.4-44-66.5 \quad \mathrm{~V}( \pm 5 \%)$ \\
\hline
\end{tabular}

The protection method that is used for power transformer depends on the transformer ratings. Mechanical relays are widely used to protect the transformer. Biased current differential protection equips the optimum overall protection [20], [21]. MATLAB/Simulink environment is used to model the transformer 
protection system. The following components are the fault simulation model are given as: i) three-phase source, ii) three-phase $\mathrm{CB}$, iii) three-phase transformer, vi) three-phase V-I measurement, v) subsystem, vi) RLC series branch, vii) scope, viii) current measurement, and xi) three-phase fault. To design a relay protective scheme, a power transformer model is essential to produce the fault records that required adjusting the fault detection system [22], [23]. The implementation was done by using MATLAB/Simulink environment.

\section{RESEARCH METHOD}

In which a 3-phase, $2 \mathrm{KVA}, 50$ to $60 \mathrm{~Hz}, 230 / 2 * 66.5 \mathrm{~V} /$ phase transformer were used. The designated differential relay consists of two input signals Ip and Is, where, Ip and Is represent the output currents respectively. Both input signals would distribute into three parallel tracks in order to be analysed. The second three signals of the secondary current will subtract from the first three signals at the primary current and the results obtained will be compared with the reference current by using comparator block [24]-[27]. Figure 6 shows the simulated conventional relay system.

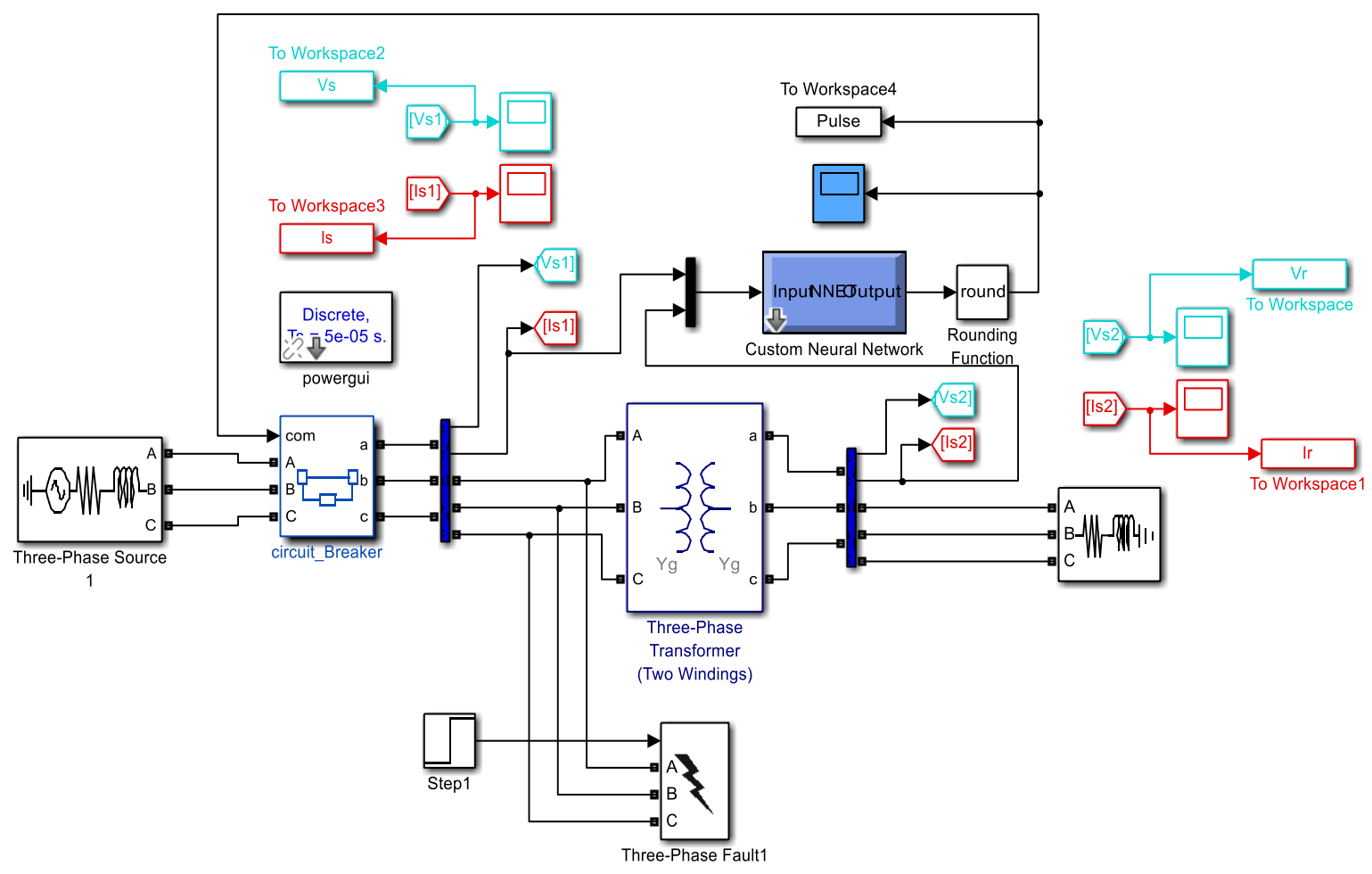

Figure 6. Modelling circuit of differential relay protection

\section{ANN TECHNIQUES}

ANN techniques initialized with a variety of parameters, and the proposed relay-based ANN was trained with 'nntool.' The number of neurons inside the input layer was determined by the number of training samples, while the target number determined the number of output neurons. Finally, using the trial and error method, the number of hidden neurons inside the hidden layer was determined. In training, lower mean square error (MSE) values are preferred, and zero MSE indicates no error, Figure 7 represents the internal structure of the proposed ANN [10].

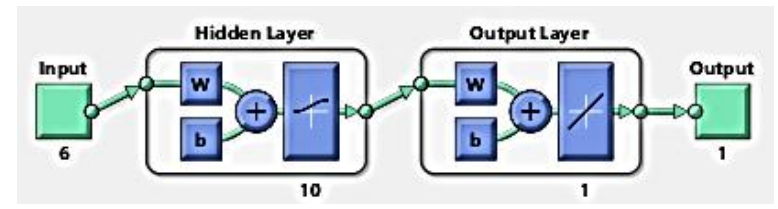

Figure 7. Artificial neural network 
Back probagation of error has wide application for detecting the internal fault. ANN is typically organize in layer were designated of a number of correlated nodes with containing the activation function. Patterns were offered to the network via the input layer, which communicated to the one or many hidden layers. Actual processing was implemented via a system connection (weighted). After that, the hidden layers were attached to the output layer as shown in the Figure 8 [10].

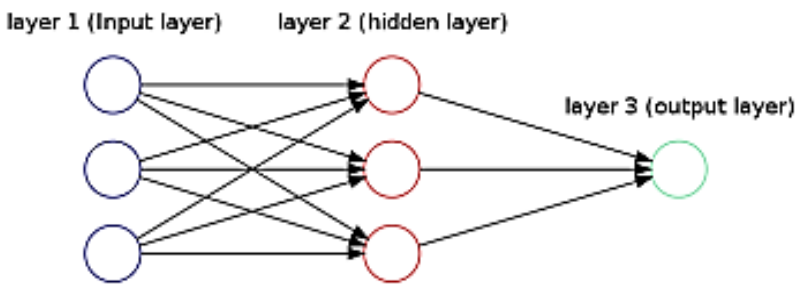

Figure 8. Internal architecture of ANN

\section{RESULTS AND DISCUSSION}

\subsection{At no fault (normal operation)}

In this portion of the simulation, the system works normally, with no faults or other disruptions, the secondary voltage and current are at the designated operating values according to the transformer turn ration $(1: 2)$, the simulation results of the primary and secondary currents as shown in Figures 9 and 10.

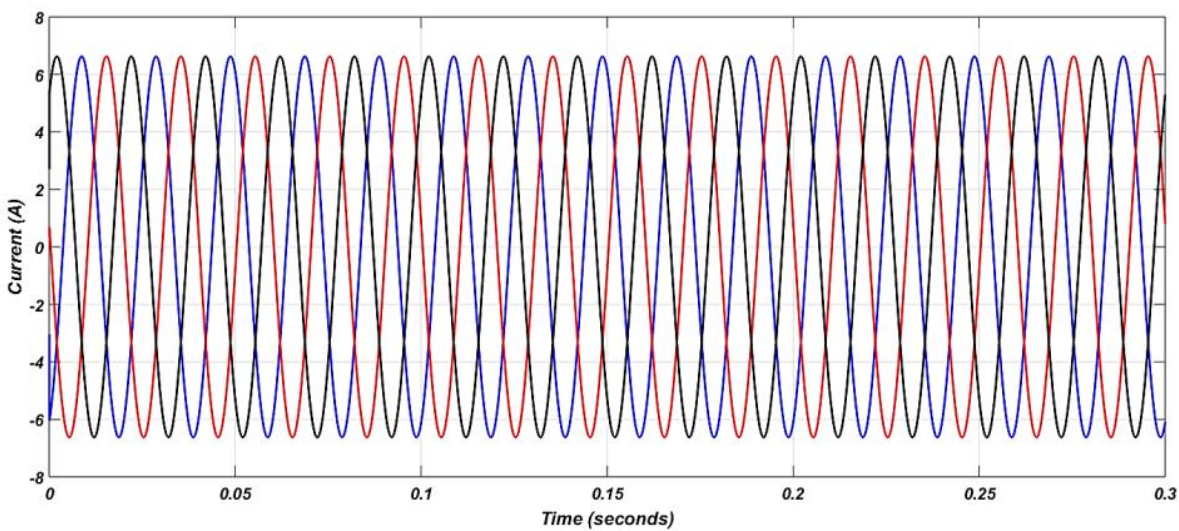

Figure 9. Primary current at no fault

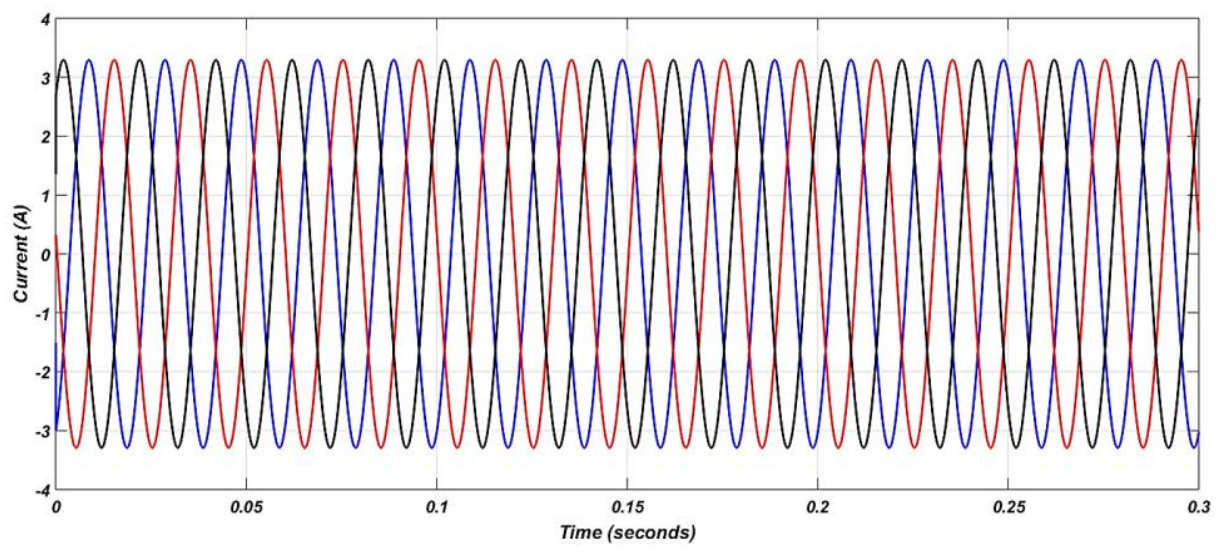

Figure 10. Secondary current at no fault 


\subsection{Internal faults (inside zone)}

Figure 11 shows the differential relay output signal sent to $\mathrm{CB}$ when the fault occurred at time $0.15(\mathrm{sec})$

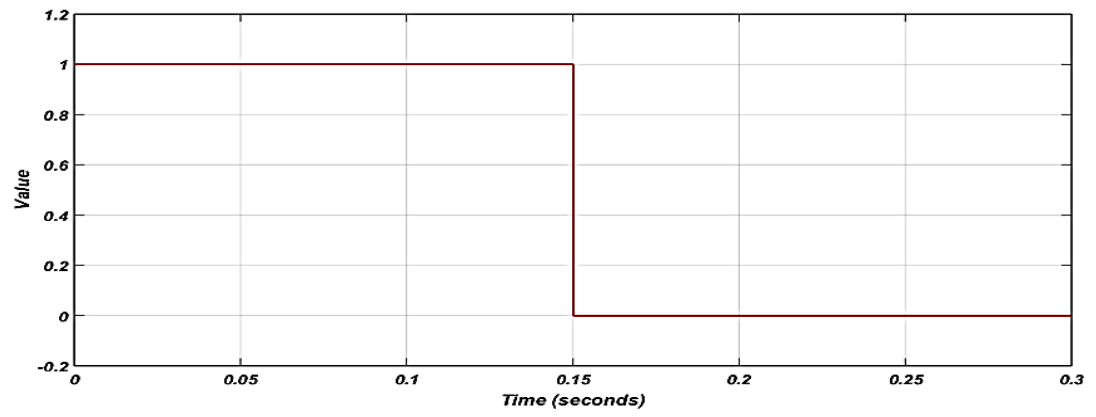

Figure 11. Differential relay signal

\subsubsection{Line-to-ground fault}

In this portion of the simulation, the line to ground fault will be applied inside the protected zone, the current signals of relay line-to-ground fault as illustrated in Figure 12.

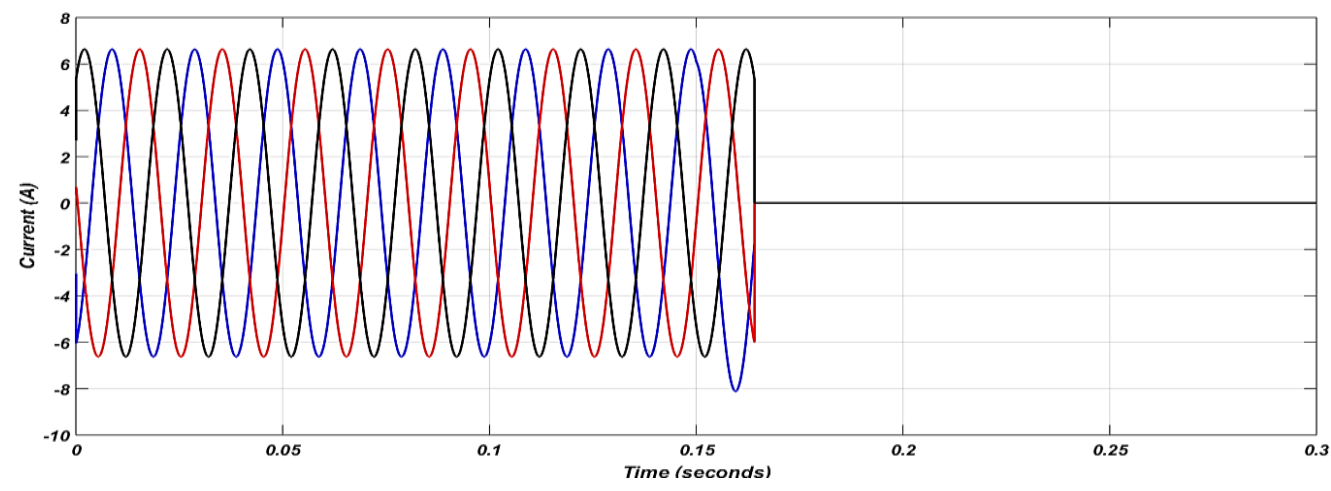

Figure 12. Current at line-to-ground fault

\subsubsection{Line-to-line-to-ground fault}

In this section of the simulation, the line-to-line-to-ground fault will be used inside the protected zone; the current signals of the relay line-to-line-to-ground fault are illustrated in Figure 13.

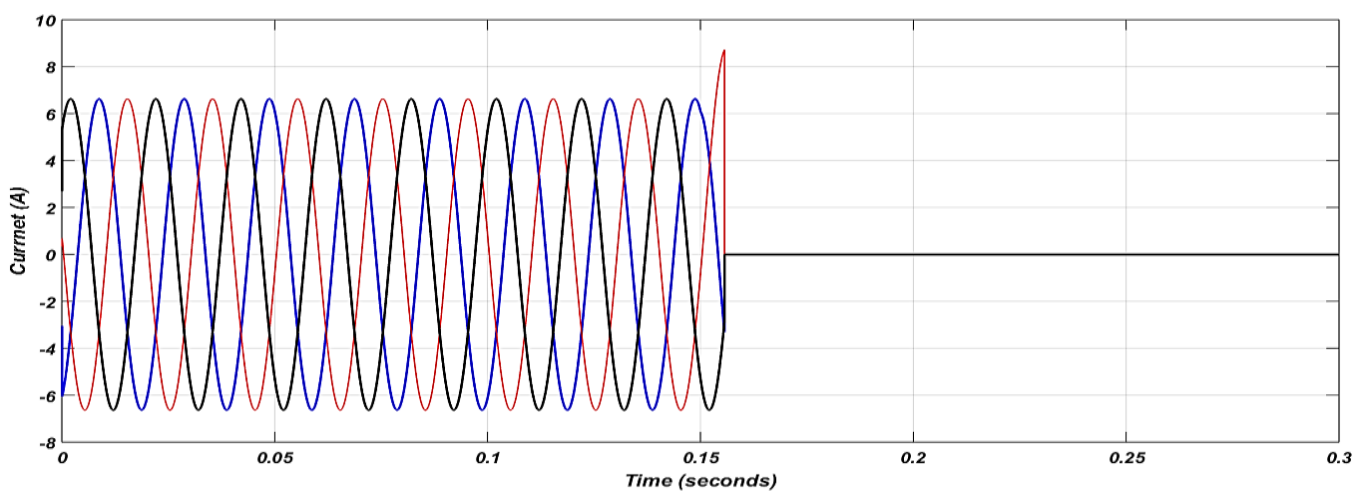

Figure 13. Current at line-to-line-to-ground fault 


\subsubsection{Triple-to-ground fault}

In this section of the simulation, the triple-to-ground fault will be used inside the protected zone, with the current signals of the relay triple-to-ground fault illustrated in Figure 14.

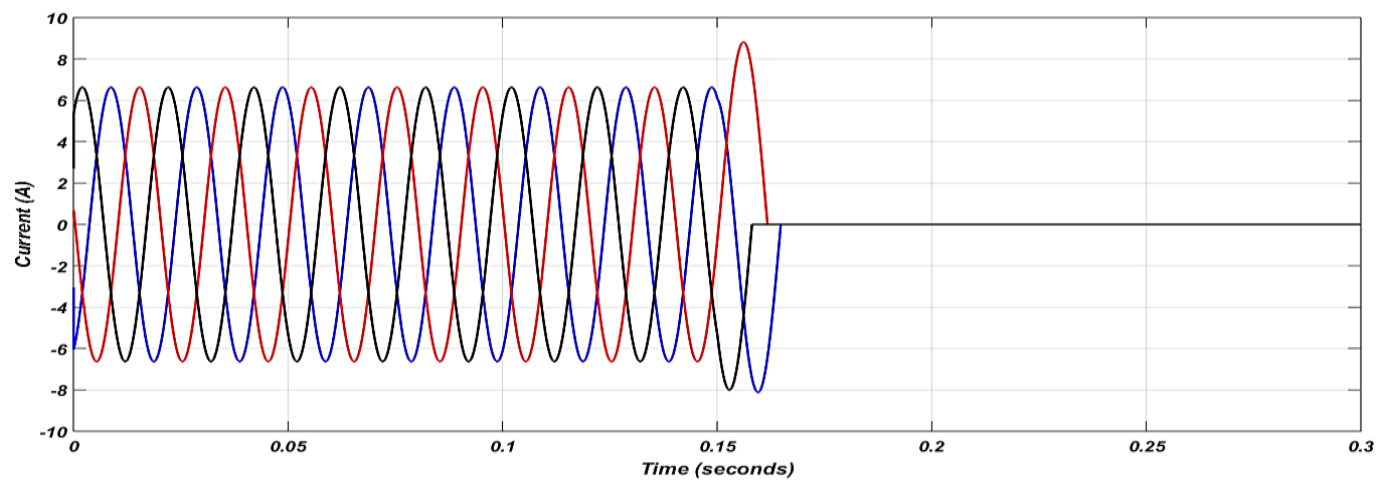

Figure 14. Current at three phase-to-ground fault

\subsubsection{Line-to-line fault}

The line-to-line fault will be used inside the protected zone in this section of the simulation, and the current signals of the relay line-to-line fault will be displayed as illustrated in Figure 15.

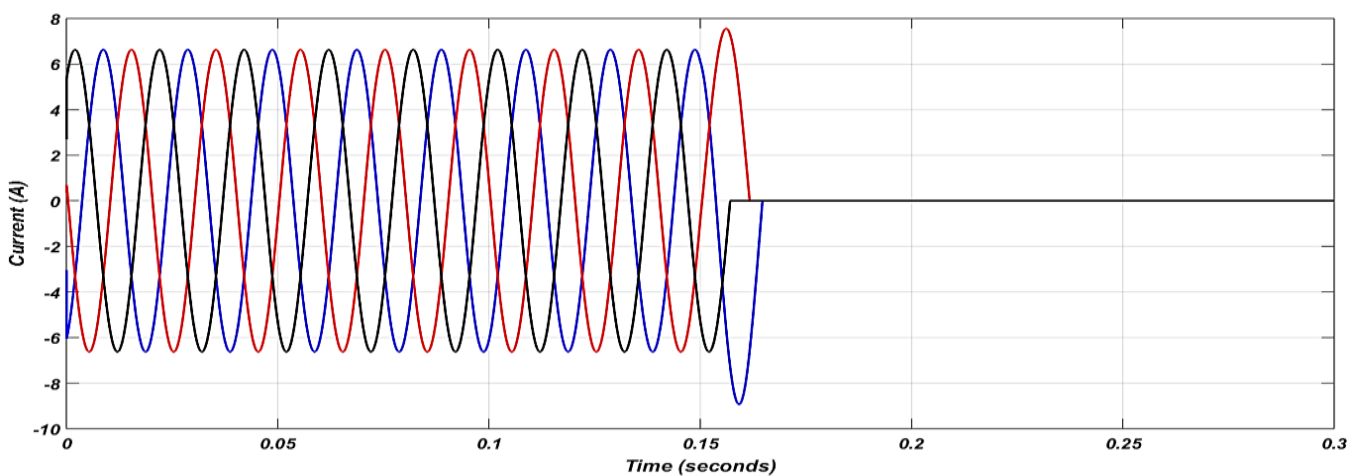

Figure 15. Current at line-to- line fault

When an internal fault occurred at $0.15 \mathrm{sec}$ as dipected in Figure 11, the ANN controller was compaied between the primary current and the secondary current, if any diffrernce occure between them it sent a trip signal was delivered from the differential relay, causing the CB to trip. After the fault time has passed, the current will be zero as the CB opened. Figures can demonstrate this 12-15.

\section{CONCLUSION}

The differential relay characteristics represented by the ANN structure in the MATLAB environment. The performance properties of a differential relay were measured at an inflicted with three phase faults. In addition, the L-G fault, L-L fault, L-L-L fault, and L-L-L-G fault were investigated. The simulation results show that the proposed differential relay provides a good solution. The suggested relay was able to handle the situation and if no fault occurred, it was from the results, the transient response for all kinds occurred at the same impulse value and same time. When a fault occurs outside of the zone (external fault), the current waveform signals from the primary side are similar to those obtained from the secondary side due to no relay operation. The current values in two phases after the fault happened in L-L-G were equal (6.5 A), but these values were different in L-L case. ANN technique was enhancement the differential relay reliability without using fourth harmonic method. 


\section{ACKNOWLEDGEMENTS}

The authors would give their gratitude to Northern Technical University-Technical College of

Engineering/Mosul for providing us with a simulation package that allowed us to complete our research.

\section{REFERENCES}

[1] B. M. SALIH, M., A. IBRAHIM, A,. N. HAMOODI, "Differential relay protection for prototype transformer," PRZEGLAD ELEKTROTECHNICZNY, vol. 1, no. 6, pp. 160-164, Jun. 2021, doi: 10.15199/48.2021.06.30.

[2] P. P. Aye, W. K. Myint, and W. T. Zar, "Modelling and simulation of protection for power transformer at primary substation by using differential protection," International Journal of Science and Engineering Applications, vol. 7, no. 11, pp. 474-478, Nov. 2018, doi: 10.7753/IJSEA0711.1014.

[3] H. Eteruddin, A. A. Mohd Zin, and B. Belyamin, "Line differential protection modeling with composite current and voltage signal comparison method," TELKOMNIKA (Telecommunication Computing Electronics and Control), vol. 12, no. 1, p. 53, Mar. 2014, doi: 10.12928/TELKOMNIKA.v12i1.1966.

[4] H. S. Kainth and G. Sharma, "A new method for differential protection in power transformer," IOSR Journal of Electrical and Electronics Engineering, vol. 9, no. 2, pp. 64-70, 2014, doi: 10.9790/1676-09246470.

[5] H. Balaga, N. Gupta, and D. N. Vishwakarma, "GA trained parallel hidden layered ANN based differential protection of three phase power transformer," International Journal of Electrical Power \& Energy Systems, vol. 67, pp. 286-297, May 2015, doi: 10.1016/j.ijepes.2014.11.028.

[6] M. A. Ibrahim, W. K. Ibrahim, and A. N. Hamoodi, "Design and implementation of overcurrent relay to protect the transmission line," International Journal of Engineering Research and Technology, vol. 13, no. 11, p. 3783, Nov. 2020, doi: 10.37624/IJERT/13.11.2020.3783-3789.

[7] G. Varghese and A. George, "Improved transformer fault classification using ANN and differential method," International Journal of Advanced Research in Electrical, Electronics and Instrumentation Engineering, vol. 2, no. 1, pp. 79-87, 2007.

[8] S. Mirayala, V. B. S. Ram, and K. S. A. R., "Protection of power transformer form various faults using ANN," ternational Journal of Research in Engineering and Technology (IMPACT: IJRET), vol. 2, no. 9, pp. 13-20, 2014.

[9] V. K. Sahu and A. P. Vaidya, "Power transformer protection using ANN, fuzzy system and Clarke's transformer," International Journal of Advances in Electronics and Computer Science, vol. 2, no. 8, pp. 82-87, 2015.

[10] B. S. Shah and S. B. Parmar, "Transformer protection using artificial neural network," International Journal of Novel Research and Development, vol. 2, no. 5, pp. 108-111, 2017.

[11] M. S. Islam and M. M. Kabir, "ANN Based discrimination of inrush and fault currents in three phase power transformer using statistical approaches," in 2019 4th International Conference on Electrical Information and Communication Technology (EICT), Dec. 2019, pp. 1-6, doi: 10.1109/EICT48899.2019.9068766.

[12] N. S. Jadhav and A. R. Thorat, "Design of a differential relay for $1000-\mathrm{kV}$ transmission line using MATLAB," in 2013 International Conference on Energy Efficient Technologies for Sustainability, Apr. 2013, pp. 1164-1168, doi: 10.1109/ICEETS.2013.6533551

[13] L. Sevov, U. Khan, and Z. Zhang, "Enhancing Power transformer differential protection to improve security and dependability," IEEE Transactions on Industry Applications, vol. 53, no. 3, pp. 2642-2649, May 2017, doi: 10.1109/TIA.2017.2670525.

[14] M. Kezunovic and Yong Guo, "Modeling and simulation of the power transformer faults and related protective relay behavior," IEEE Transactions on Power Delivery, vol. 15, no. 1, pp. 44-50, 2000, doi: 10.1109/61.847227.

[15] A. Guzman, Z. Zocholl, G. Benmouyal, and H. J. Altuve, “A current-based solution for transformer differential protection. I. Problem statement," IEEE Transactions on Power Delivery, vol. 16, no. 4, pp. 485-491, 2001, doi: 10.1109/61.956726.

[16] M. Tripathy, "Power Transformer Differential Protection Based on Neural Network Principal Component Analysis, Harmonic Restraint and Park's Plots," Hindawi Publishing Corporation Advances in Artificial Intelligence, vol. 2012, pp. 1-9, 2012, doi:10.1155/2012/930740.

[17] F. Namdari, S. Jamali, and P. A. Crossley, "Power differential based wide area protection," Electric Power Systems Research, vol. 77, no. 12, pp. 1541-1551, Oct. 2007, doi: 10.1016/j.epsr.2006.10.018.

[18] J. Azarakhsh, "The power transformer differential protection using decision tree," Bulletin de la Société Royale des Sciences de Liège, vol. 86, pp. 726-738, 2017, doi: 10.25518/0037-9565.6982.

[19] A. M. Shah and B. Bhalja, "A new adaptive differential protection scheme for tap changing power transformer," International Journal of Emerging Electric Power Systems, vol. 16, no. 4, pp. 339-348, Aug. 2015, doi: 10.1515/ijeeps-2015-0005.

[20] A. Shobole, M. Baysal, M. Wadi, and M. R. Tur, "Protection coordination in electrical substation part-2 unit protections (differential and distance protection) -case study of Siddik Kardesler Substation (SKS), Istanbul, Turkey," GAZI UNIVERSITY JOURNAL OF SCIENCE, vol. 30, no. 4, pp. 163-178, 2017.

[21] M. Rasoulpoor, "Discrimination between inrush and short circuit currents in differential protection of power transformer based on correlation method using the wavelet transform," Iranica Journal of Energy \& Environment, 2011, doi: 10.5829/idosi.ijee.2011.02.04.3139.

[22] F. Romanyuk, I. Novash, M. Loman, and P. Wegierek, "Validation of mathematical model of differential protection," Przeglad electrotechniczny, vol. 90, no. 3, pp. 187-190, 2014, doi: 10.12915/pe.2014.03.42.

[23] T. Zheng, S.-T. Cha, Y.-H. Kim, P. A. Crossley, S. H. Lee, and Y. C. Kang, "Design and evaluation of a protection relay for a wind generator based on the positive- and negative-sequence fault components," Journal of Electrical Engineering and Technology, vol. 8, no. 5, pp. 1029-1039, Sep. 2013, doi: 10.5370/JEET.2013.8.5.1029.

[24] E. Ali, A. Helal, H. Desouki, K. Shebl, S. Abdelkader, and O. P. Malik, "Power transformer differential protection using current and voltage ratios," Electric Power Systems Research, vol. 154, pp. 140-150, Jan. 2018, doi: 10.1016/j.epsr.2017.08.026.

[25] B. Bahmanifirouzi, J. Masoud, and M. Nafar, "A sensitive method for identifying winding turn to turn faults in power transformer," Australian Journal of Basic and Applied Sciences, vol. 5, no. 7, pp. 303-307, 2011.

[26] R. B. Dhumale, "Fault detection and diagnosis of high speed switching devices in power inverter," International Journal of Research in Engineering and Technology, vol. 04, no. 02, pp. 253-257, Feb. 2015, doi: 10.15623/ijret.2015.0402033.

[27] M. Ibrahim, B. M. Salih, and M. N. Abd, "Protection transformer and transmission line in power system based on MATLAB Simulink," PRZEGLĄD ELEKTROTECHNICZNY, vol. 1, no. 10, pp. 19-23, Sep. 2021, doi: 10.15199/48.2021.10.04. 


\section{BIOGRAPHIES OF AUTHORS}

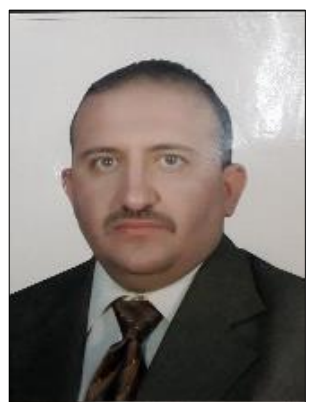

Ali Nathim Hamoodi (iD) 8 Sc P Teacher Department of Electrical Power Technologies Engineering. Master's degree (2000), and Ph.D. (2011) in electrical engineering, from the University of Aleppo, Syria. Currently, Research published in international journals, Scopus containers and science Seven, and Five internal and sponsored conferences. His specializing in the Electrical Power Engineering and he is working as a lecturer in Northern Technical University, Technical College of Engineering-Mosul-Iraq. He can be contacted at email: ali_n_hamoodi74@ntu.edu.iq.

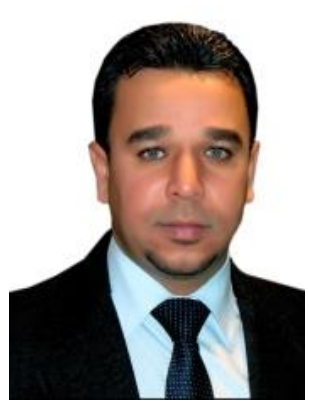

Mohammed Ahmed Ibrahim (iD S SC P Teacher Department of Electrical Power Technologies Engineering. Bachelor's degree from the Northern Technical University 2005 in Electrical Engineering. Master's degree from the Northern Technical University in (2011) in Electrical Engineering. Research published in international journals, Scopus containers and science Seven, and Five internal and sponsored conferences. His specializing in the Electrical Power Engineering and he is working as a lecturer in Northern Technical University, Technical College of Engineering Mosul-Iraq. He can be contacted at email: Mohammed.a.ibrahim1981@ntu.edu.iq.

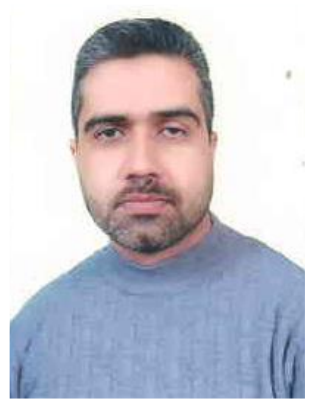

Bashar Muhammed Salih (D) 8d SC P Teacher Department of Electrical Power Technologies Engineering. From the University of Technology 1997 in Electrical and Electronic Engineering/State of Iraq Master's degree from the University of Technology 2005 in Electrical and Electronic Engineering/State of Iraq Six published research papers in international scientific journals, Scopus containers, and Science Five internal and sponsored conferences and seminars. He can be contacted at email: basharms_tecm@ntu.edu.iq. 